\title{
BLICKDIAGNOSE
}
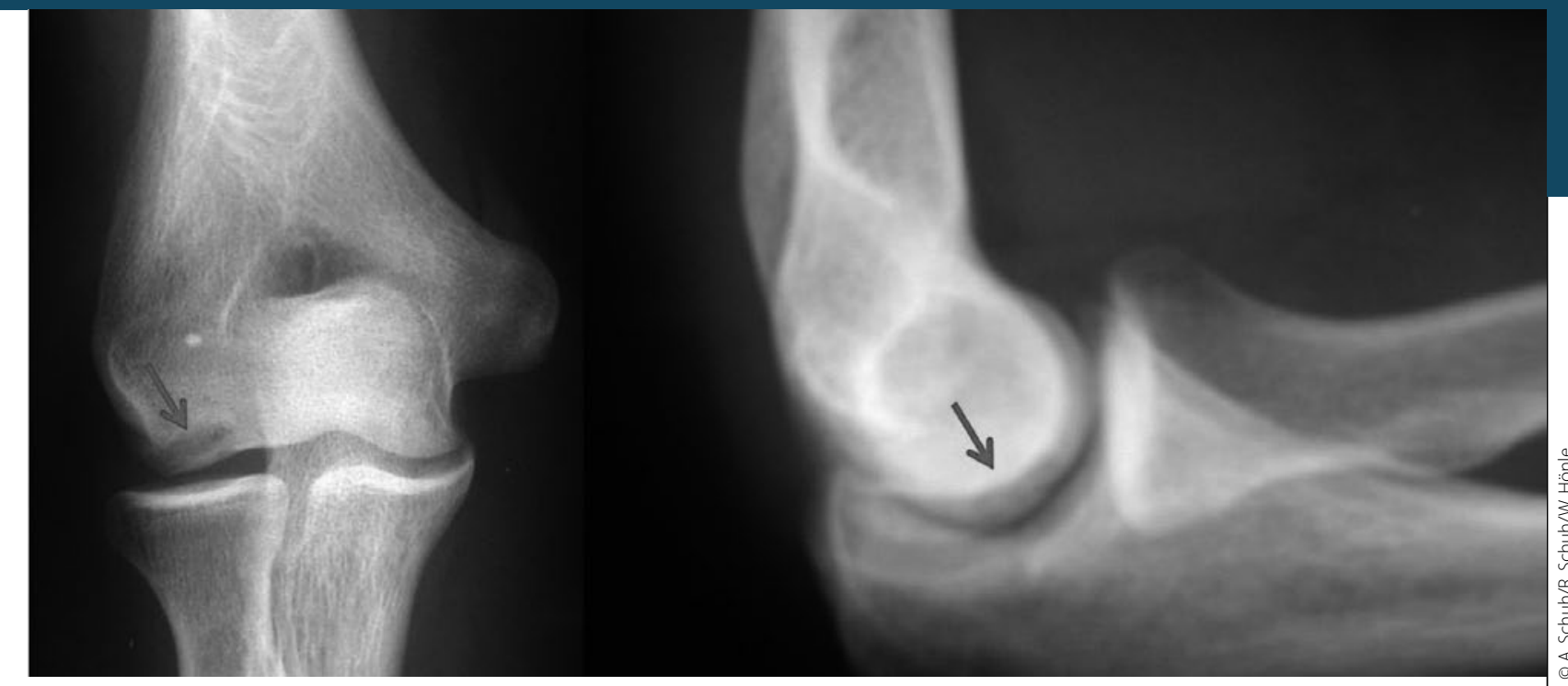

Seit zwei Jahren Schmerzen im rechten Ellenbogen

\section{Bewegung ist nicht eingeschränkt}

Ein 15 Jahre alter Patient stellt sich wegen seit zwei Jahren bestehenden belastungsabhängigen Schmerzen des rechten Ellenbogengelenkes vor. Klinisch findet sich eine freie Beweglichkeit des rechten Ellenbogen mit Extension/Flexion 10/0/140 ${ }^{\circ}$, Supination/Pronation $90 / 0 / 90^{\circ}$. Es lässt sich ein isolierter Druckschmerz über dem ventralen Capitulum humeri auslösen.

— Die Röntgenaufnahme des rechten Ellenbogens in zwei Ebenen zeigt eine zystische Auflockerung des Capitulum humeri im Sinne eines M. Panner, Stadium II.

1927 beschrieb Hans J. Panner (Radiologe, Kopenhagen, 1871-1930) zum ersten Mal die aseptische Knochennekrose der oberen Extremität im Bereich des Ellenbogengelenkes und bezeichnete sie als "Morbus Perthes des Ellenbogens". Es ist die häufigste avaskuläre Nekrose im Bereich des Ellenbogens und verläuft in den typischen Stadien einer aseptischen Knochennekrose.

In der Regel tritt die Erkrankung im Alter von sieben bis zwölf Jahren auf, Jungen sind deutlich häufiger betroffen als Mädchen, die rechte Seite ist deutlich häufiger betroffen als die Linke. Die Ursache ist bislang nicht geklärt.

Klinisch findet man in der Regel uncharakteristische Beschwerden im Ellenbogen mit örtlichem Druckschmerz und selten eine leichte Bewegungseinschränkung. Gelegentlich besteht eine tastbare Schwellung. Einklemmungserscheinungen liegen in der Regel nicht vor. Für das Nativröntgen sowie die MRT bzw. die CT-Untersuchung sind vier Stadien beschrieben:

- Stadium I (Sklerosierungsstadium): Subchondral betonte Verdichtungen des Knochens.

- Stadium II (Fragmentationsstadium): Auflockerung der gelenkflächennahen Binnenstrukturen.

- Stadium III (Destruktionsstadium): Knöcherne Destruktion mit Größenreduktion der Epiphyse.

- Stadium IV (Reparationsstadium): Regeneration der Epiphyse. In der Regel ist die konservative Therapie vollkommen ausreichend. Es erfolgt die temporäre Ruhigstellung und Sportkarenz (dies gilt in besonderem Maße für Wurfsportarten). Die Ausheilung erfolgt innerhalb von ein bis drei Jahren. Eine analgetisch-antiphlogistische Therapie ist selten erforderlich. Die Prognose ist gut, es kommt zur Restitutio ad integrum. In den seltenen Fällen des Überganges zu einer Osteochondrosis dissecans kann die operative Sanierung (Pridie-Bohrungen, Entfernung freier Gelenkkörper) erforderlich werden.

Keywords: Panner's Disease, Osteochondrosis, capitulum of distal humerus

- PD Dr. med. habil. Alexander Schuh ${ }^{(1)}$, Dr. med. Ralph Schuh ${ }^{(2),}$ Dr. med. Wolfgang Hönle ${ }^{(1)}$,

(1) Muskuloskelettales Zentrum Neumarkt, Klinikum Neumarkt,

Nürnbergerstraße 12, D-92318 Neumarkt in der OPf.

(2) OrthMed Weiden 